\title{
Bond repair of cracked beams
}

\author{
H. Cruz ${ }^{1}$, J. Custódio ${ }^{1} \&$ D. Smedley ${ }^{2}$ \\ ${ }^{I}$ Structures Department, Wood Structures Division, \\ Laboratório Nacional de Engenharia Civil, Portugal \\ ${ }^{2}$ Rotafix, Rotafix Ltd., Rotafix House, Abercraf, Swansea, UK
}

\begin{abstract}
The repair of cracked timber beams on site frequently involves crack injection with adhesives followed by the application of the chosen strengthening system, involving bonded or bolted metal plates or rods or bonded pultruded GFRP or CFRP profiles. Although strengthening design will not generally take into account the contribution of injecting adhesives in the crack volume region it is felt that this contribution to overall strengthening of the component or structure may be of some significance. A test programme was therefore developed at LNEC to assess the strength and stiffness of timber beams which were treated with epoxy adhesives after they had developed failure in a 4 point bending test. It is recognised that partially broken beams may have very narrow, almost invisible, fissures, which are difficult to impregnate. As well as the forgoing partially separated broken beams may present extremely irregular split ends, which are difficult to bring back into perfect alignment and contact. These two factors may reduce the effectiveness of the strength restoration and were considered in the experimental study. However, the specific beam failure appearance is not likely to give a clear indication of how efficient the consolidation turns out to be. Test results show that epoxy adhesive injection of cracked timber beams may lead to a not insignificant, but somewhat variable, strength recovery $(0.45$ to 1.11$)$ and to a significant stiffness recovery ( 0.74 to 0.99) of broken beams. Having these results in mind, although on site repair of broken timber beams should not rely on epoxy adhesives injection only, its contribution to the stiffness of strengthened beams is significant and one should make use of this advantage.
\end{abstract}

Keywords: cracked timber beams, structural adhesives, consolidation, strength and stiffness recovery. 


\section{Introduction}

Old timber structural members may present failure due to biological damage, which is responsible for timber strength reduction or cross section loss, or due to unacceptable stresses resulting from inadequate design or from structural accidental or intentional modifications. Furthermore older structures intended for a particular purpose are currently being subjected to types of use for which the original design parameters were not intended.

Although the replacement of damaged members by new timber or other materials may seem the easiest solution, on site repair may be a better cost option in cases where only a small timber length is damaged, or when that member is part of a complex structural system and its removal may jeopardise decorative ceilings and/or limit the occupancy of the building, Even the replacement of one carrier beam may with traditional and well-proven carpentry techniques involve the whole or partial removal of a roof structure with its corresponding time and cost delay. In fact removal of sound surrounding components often puts hitherto undamaged and adequate parts of the structure at risk.

The repair of cracked timber beams on site frequently involves crack injection with adhesives followed by the application of the chosen strengthening system, namely involving bonded or bolted metal plates or rods or bonded glass fibre profiles. It is interesting to note that in the early days of injection technology with timber (borrowed from Concrete repair practice in the late 1950's early 1960's) attempts were made to restore overstressed classical truss rafter systems with inappropriate low viscosity 2 part epoxy so-called injection systems (Ref Aberdeen Music Hall) - the lack of success resulted in a secondary repair method using bolted ' $U$ ' beam sections.

Current strengthening design will not generally take into account the contribution of injecting adhesives in the cracked area, so-called consolidation. It is felt that this contribution might be significant. There was also the question as to whether it would be possible to identify in advance some typical failure configurations likely to benefit in practice from the so-called consolidation technique.

A test programme was therefore developed at LNEC with the intention of assessing the strength and stiffness of timber beams which were consolidated with epoxy adhesives after they had developed failure in 4 point bending tests.

References to studies involving timber crack injection could not be found in the literature, although they have some similarity with glued timber delamination repair. For the specific case of crack consolidation, with complex irregular surfaces of the adherend it is necessary to find adhesives with suitable rheology. Thick gap-filling adhesive which usually contain fillers are not deemed to be suitable, whereas very fluid adhesives will penetrate more easily but will not be capable of filling small voids left inside the timber member, reducing bonding efficiency at those points. This was observed in previous trials by the authors [1], where a poor crack consolidation (and corresponding low strength recovery) was obtained by the combined use of a thick gap-filling adhesive followed by 
injection with a very fluid one. To avoid this problem, a thixotropic adhesive was used in the current experimental programme.

Another peculiarity of this kind of repair lies in the fact that preparation of clean bonding surfaces is not possible. Wood surface oxidation and any possible air borne or liquid contamination will have taken place since the time between fracture and repair intervention could be days or even years depending upon discovery of the fracture and application of the chosen remedial solution.

\section{Materials and method}

Test specimens consisted of sixteen 1500x120x70 mm Maritime pine (Pinus pinaster, Ait.) timber beams. Timber defects like knots were within the limits of the EE strength grade defined in NP4305 [2], although no restrictions concerning the presence of pith and the associated juvenile wood (which is not allowed in grade EE) were imposed.

Two series of beams were studied: 1 to 10 and A to F. Every beam was first tested up to failure, in 4-point bending, to evaluate its maximum strength and modulus of elasticity. Moisture content of timber varied between $12 \%$ and $14 \%$ $($ mean value $=13 \%)$.

After a period of time (making approximately nine months for beams 1-10 and fifteen months for beams A-F), each beam was consolidated with the thixotropic epoxy adhesive standard Slow Set CB10T, from ROTAFIX. No regularization of the split ends was done and the beams were brought back to the initial (straight) shape by using clamps and steel bars which were removed after adhesive cure.

Two months later, the consolidated beams were subjected to a 4-point bending test again. The same tension edge was chosen in both the bending tests, before and after consolidation.

Moisture content of timber at the time of the second bending test was checked with the electrical moisture meter and it was seen to be similar to their initial value.

Bending tests were carried out in general accordance with the specifications of EN408 [3].

The $1.50 \mathrm{~m}$ long specimens, simply supported over a span of $1.40 \mathrm{~m}$, were symmetrically loaded in bending at two points $0.50 \mathrm{~m}$ apart. Small steel plates, $5 \mathrm{~cm}$ large, were inserted between the test piece and the loading heads, and between the test piece and the supports, to minimise local indentation (figure 1).

The total load $\boldsymbol{F}$ (equal to the sum of the vertical loads at the two load points) was applied at a constant displacement rate of $1 \mathrm{~cm} / \mathrm{min}$. Total deformation $\left(\boldsymbol{w}_{\text {total }}\right)$ was measured at mid span, at mid depth of the cross section.

Bending strength and elasticity modulus of each beam were to be assessed in a single test; therefore, the referred displacements were measured till failure.

The global modulus of elasticity in bending was determined by applying the relevant equations in EN 408 [3]. 


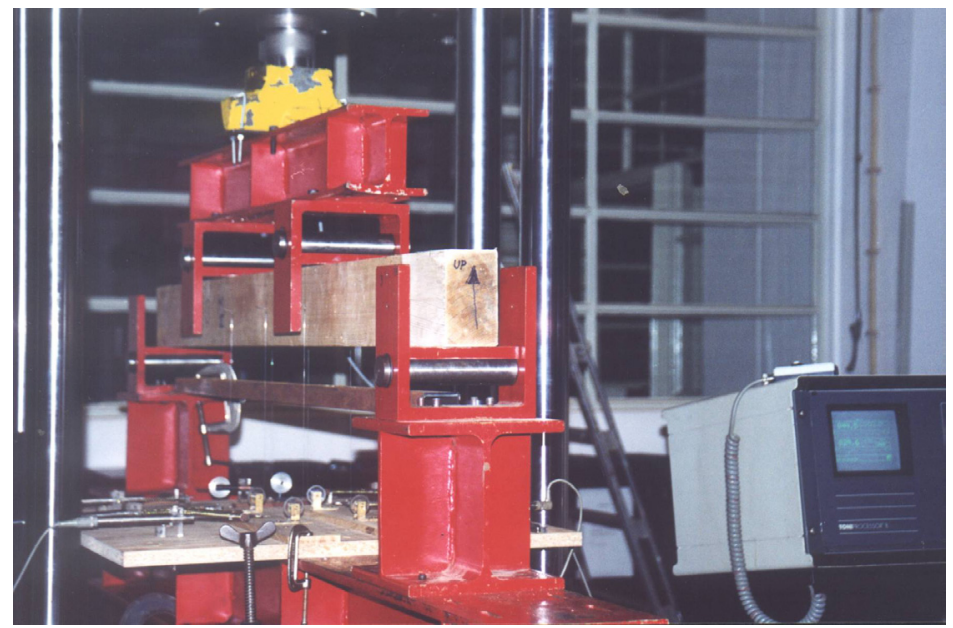

Figure 1: $\quad$ Test set up and specimen being tested in bending.

\section{Test results and discussion}

Table 1 presents individual test results in the first (initial sound state) and in the second (consolidated) round of tests, concerning the global modulus of elasticity and bending strength.

In annex $\mathrm{A}$ are presented some examples of the beams after the second round of bending tests. The fibre separation lines on both faces and bottom edge are enhanced on the photos (fine lines for old cracks - before consolidation, thick lines for cracks developed on the consolidated beams).

Load-deformation diagrams obtained for each beam, in both rounds of bending tests (initial state and consolidated beam), are presented in the annex B.

The average recovery of strength due to consolidation with the epoxy adhesive was 0.72 (ranging from 0.45 to 1.11 ). In most cases, the initial part of the load-displacement test diagrams obtained before and after consolidation were very similar. Therefore, similar global modulus of elasticity was obtained -0.90 efficiency was obtained with individual beams (ranging from 0.74 to 0.99 ).

This seems to indicate that consolidation was effective till a certain point under moderate loads - although it was not enough to recover the performance of the solid timber beam for stress levels closer to the initial bending strength.

This is confirmed by the fact that bending failure in the consolidated beams generally affected the same material, that is to say that it occurred in the same areas where the initial beam had previously failed.

There is not a clear correspondence between crack pattern and efficiency of the repair: apparently similar cracks have conducted to distinct results within the range of strengthening values obtained.

Despite the small number of beams in each group, there is no clear distinction between groups 1-10 and A-F. In both cases, the application of the epoxy 
adhesive took place several months after failure, thus simulating the application of adhesive to old timber surfaces.

Table 1: Global modulus of elasticity and bending strength for initial beams and beams after consolidation (ini/cons).

\begin{tabular}{||c|c|c|c|c|c|c||}
\hline \multirow{2}{*}{ Beam } & \multicolumn{3}{|c|}{ Modulus of Elasticity (MPa) } & \multicolumn{3}{|c|}{ Maximum Load (KN) } \\
\cline { 2 - 7 } & $\mathbf{E}_{\text {ini }}$ & $\mathbf{E}_{\text {cons }}$ & $\mathbf{E}_{\text {cons }} / \mathbf{E}_{\text {ini }}$ & $\mathbf{F}_{\text {ini }}$ & $\mathbf{F}_{\text {cons }}$ & $\mathbf{F}_{\text {cons }} / \mathbf{F}_{\text {ini }}$ \\
\hline 1 & 11921 & 9684 & 0.81 & 29.88 & 14.00 & 0.47 \\
\hline 2 & 16193 & 15504 & 0.96 & 56.99 & 63.13 & 1.11 \\
\hline 3 & 17371 & 14680 & 0.85 & 45.74 & 20.77 & 0.45 \\
\hline 4 & 12479 & 12033 & 0.96 & 43.93 & 33.18 & 0.75 \\
\hline 5 & 12504 & 10660 & 0.85 & 31.49 & 20.93 & 0.66 \\
\hline 6 & 13378 & 12843 & 0.96 & 41.10 & 42.48 & 1.03 \\
\hline 7 & 11706 & $(1102)$ & - & 32.68 & 6.11 & - \\
\hline 8 & 15261 & 15105 & 0.99 & 40.42 & 33.84 & 0.84 \\
\hline 9 & 14431 & 12162 & 0.84 & 44.39 & 24.26 & 0.55 \\
\hline 10 & 15683 & 14989 & 0.96 & 50.40 & 27.49 & 0.55 \\
\hline Mean (1-10) & & & $\mathbf{0 . 9 1}$ & & & $\mathbf{0 . 7 1}$ \\
\hline A & 14169 & 10519 & 0.74 & 59.05 & 43.54 & 0.74 \\
\hline B & 13364 & 11668 & 0.87 & 44.54 & 36.68 & 0.82 \\
\hline C & 14183 & 13913 & 0.98 & 51.66 & 27.49 & 0.53 \\
\hline D & 12636 & 11400 & 0.90 & 48.39 & 23.42 & 0.48 \\
\hline E & 13565 & 12345 & 0.91 & 58.67 & 55.30 & 0.94 \\
\hline \hline
\end{tabular}

\section{Conclusions}

It is recognised that partially broken beams may have very narrow, almost invisible, fissures, which are difficult to impregnate. Together with the fact that partially separate broken beams may present extremely irregular split ends, which are difficult to bring back into perfect contact. These two factors may reduce the effectiveness of the consolidation and were considered in the experimental study. However, the specific beam failure appearance is not likely to give a clear indication of how efficient the consolidation turns out to be.

Nevertheless, test results show that epoxy adhesive injection of cracked timber beams may lead to a not negligible, but somehow variable, strength recovery ( 0.45 to 1.11$)$ and to a significant stiffness recovery $(0.74$ to 0.99$)$ of broken beams.

Having these results in mind, although on site repair of broken timber beams should not rely on epoxy adhesives injection only, its contribution to the stiffness of strengthened beams is significant and should not be ignored. 
544 High Performance Structures and Materials III

\section{Annexes}

Annex A

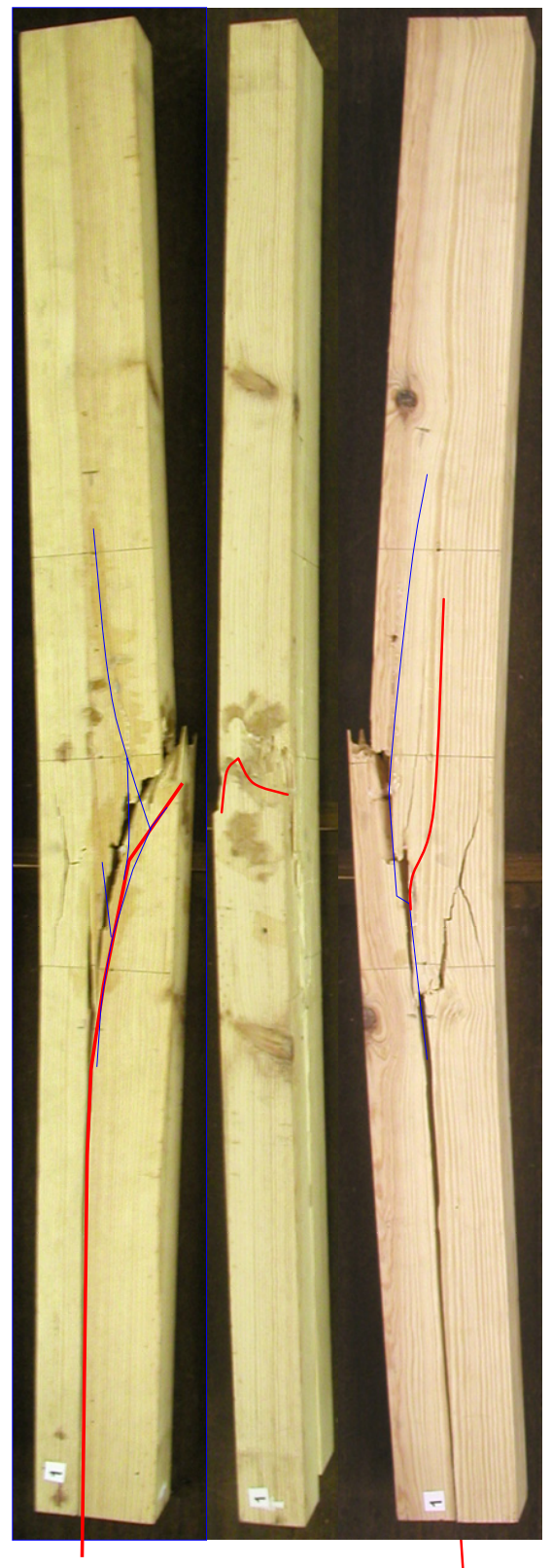

Beam 1

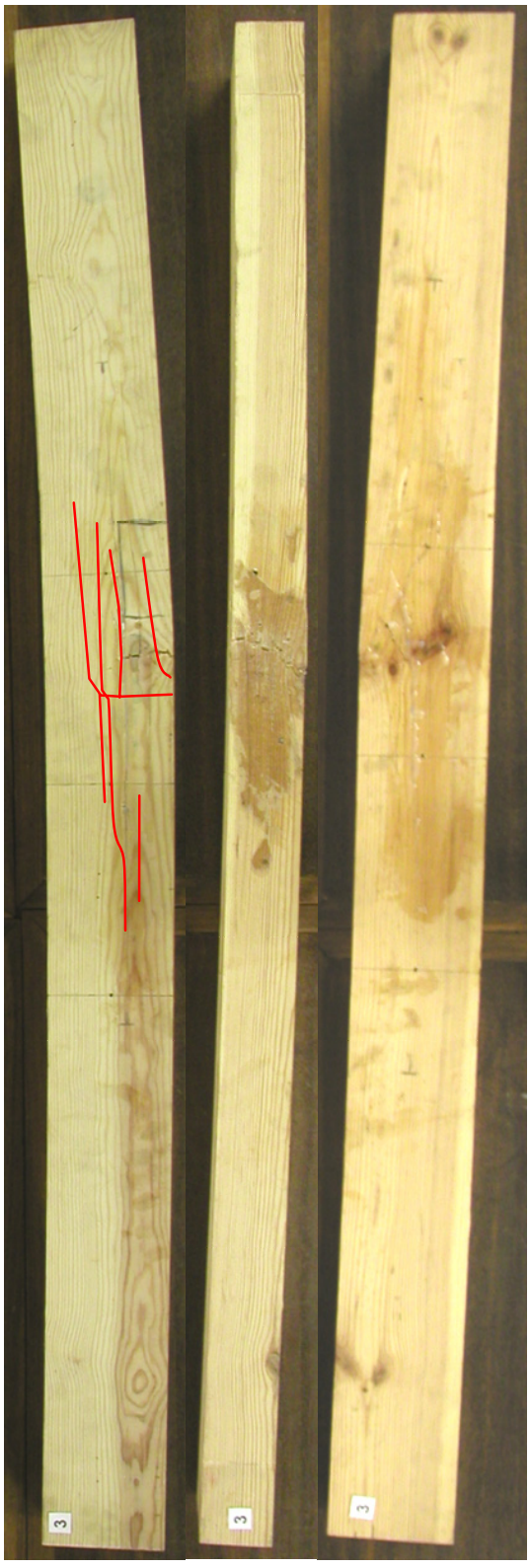

Beam 3

WIT Transactions on The Built Environment, Vol 85, (C) 2006 WIT Press

www.witpress.com, ISSN 1743-3509 (on-line) 
High Performance Structures and Materials III 545

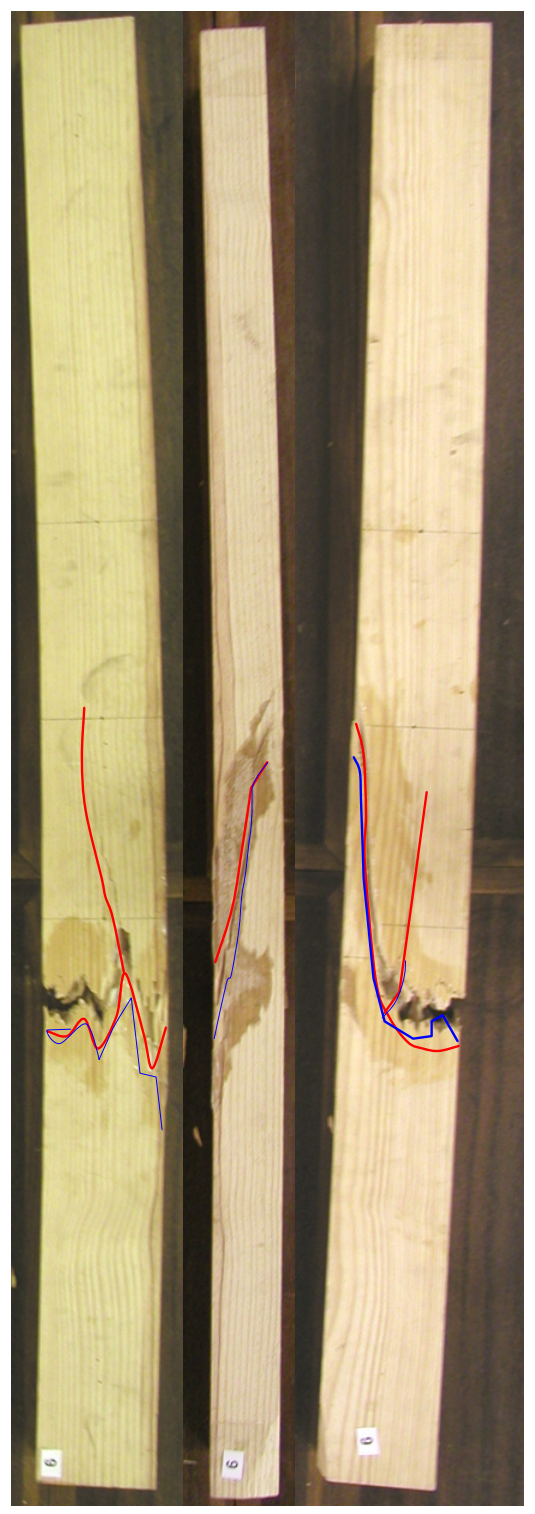

Beam 6

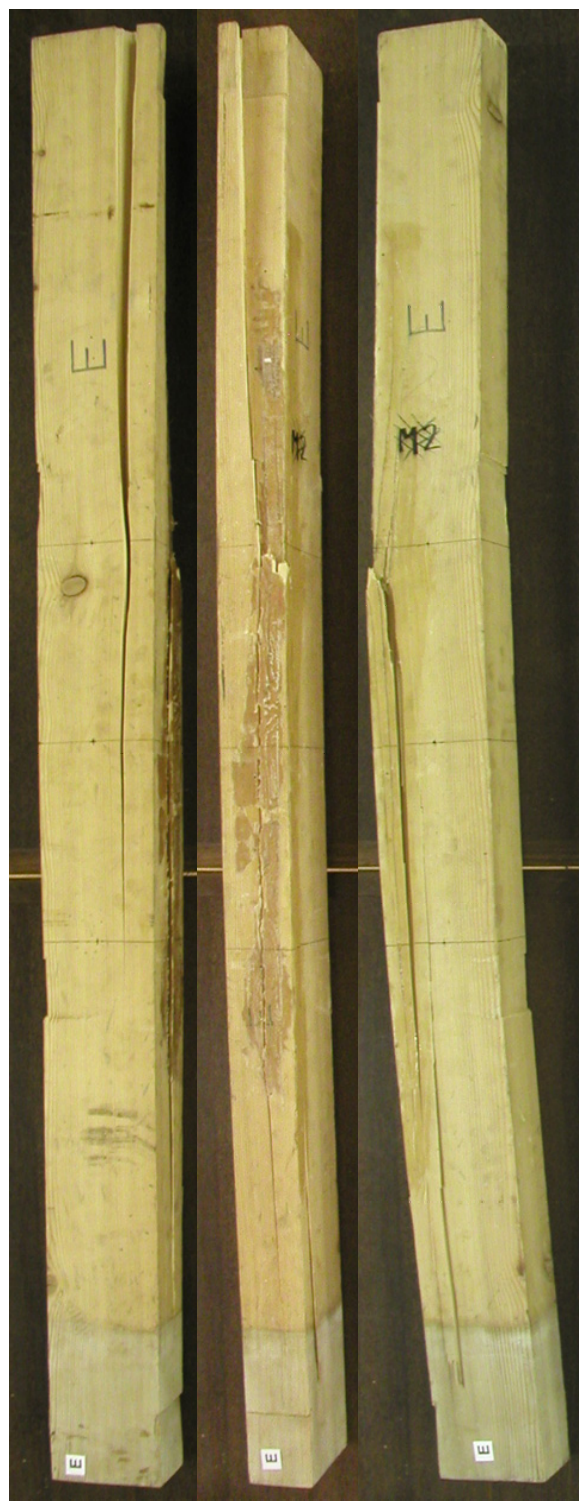

Beam E 


\section{Annex B}
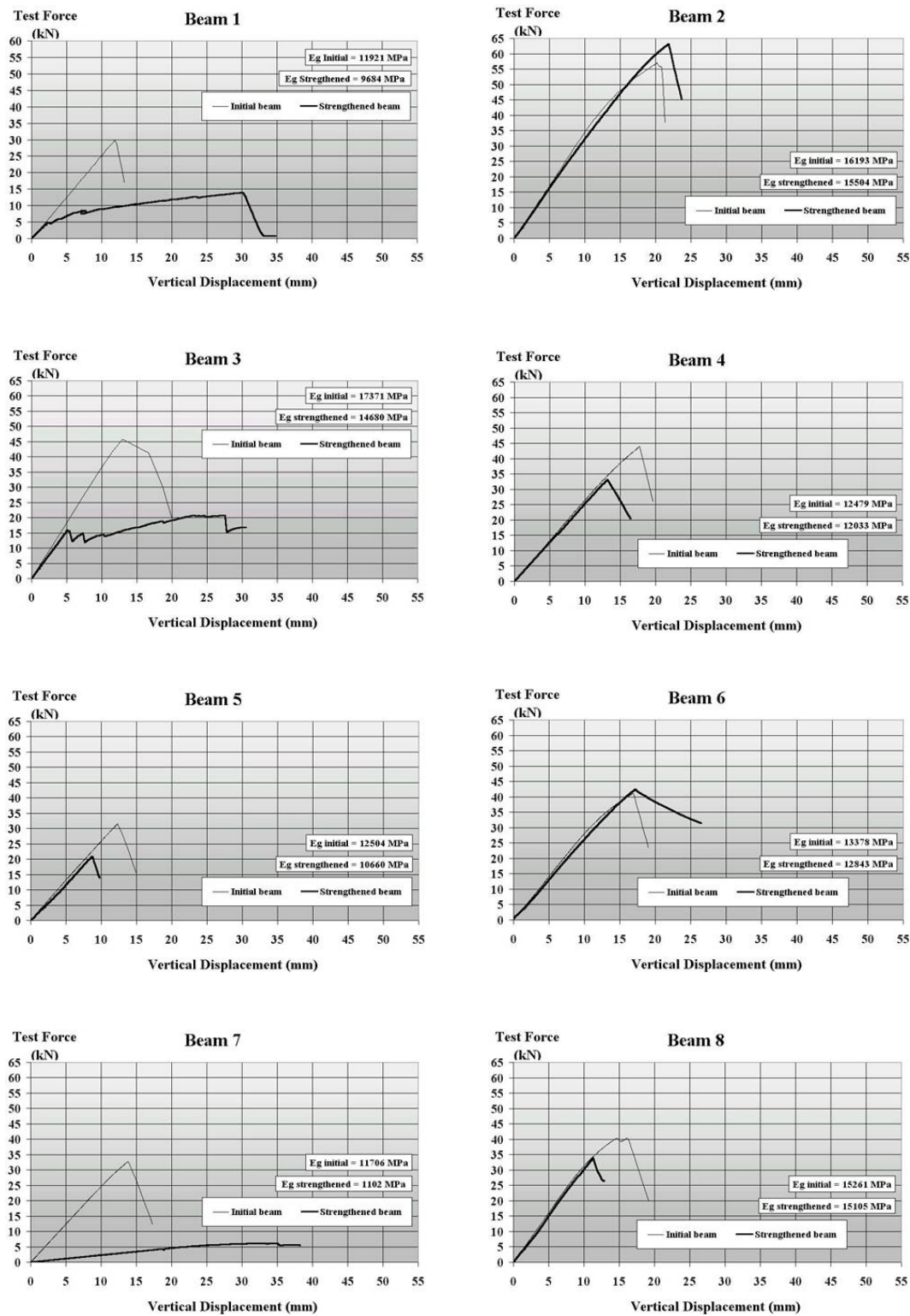

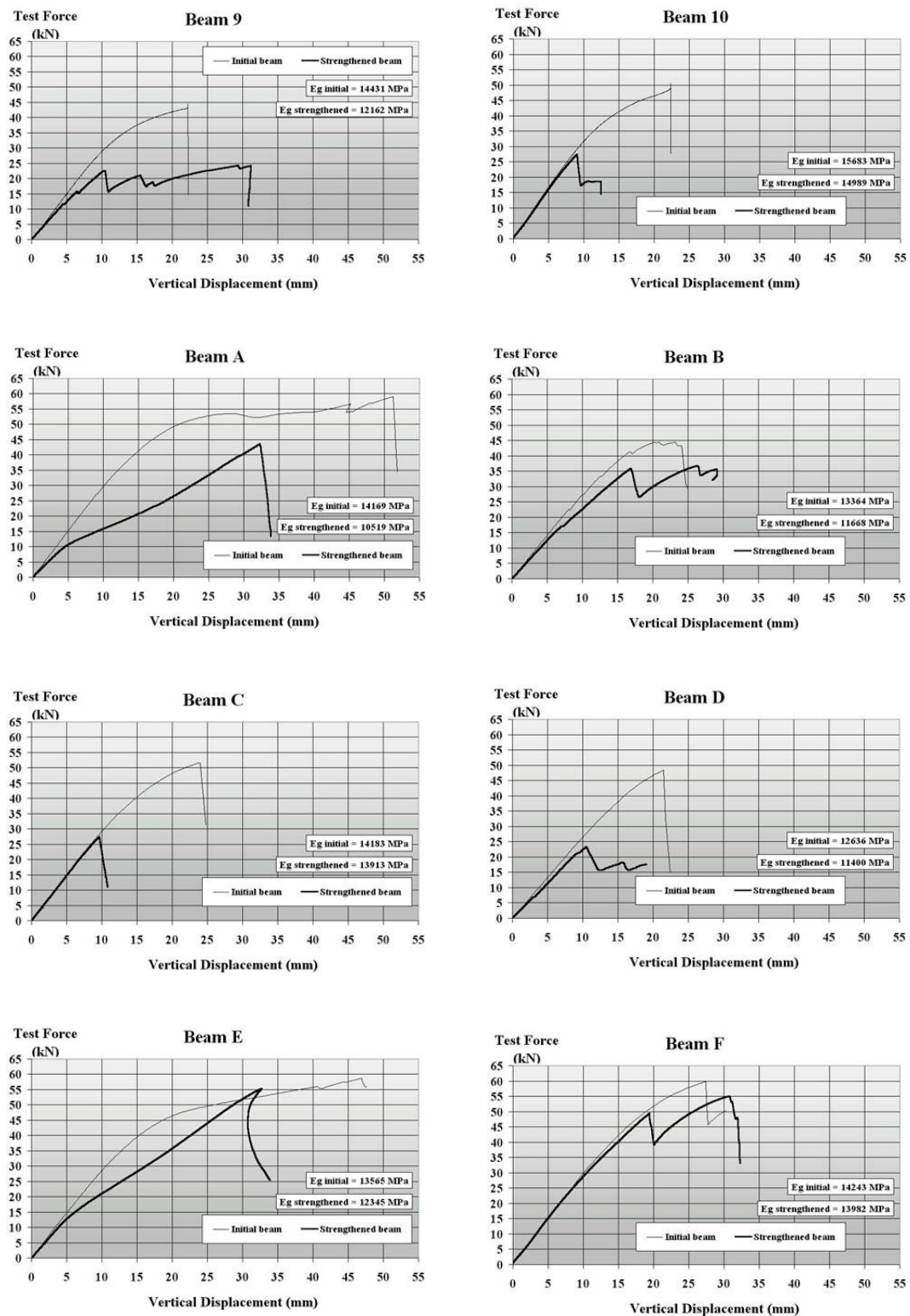

\section{Acknowledgement}

This work was carried out in the scope of the European Research Project CRAFT-1999-71216 LICONS - "Low Intrusion Conservation Systems for Timber Structures" (www.licons.org), which had a much wider scope. 
The authors wish to thank STAP (www.stap.pt) for carrying out crack consolidation and ROTAFIX (www.rotafix.co.uk) for providing the thixotropic adhesive used in this study.

\section{References}

[1] COLORETIM CT 98-9548, COmposites LOcal REinforcement for TIMber structures, Final Report - "Consolidating tests: bending tests on timber beams strengthened with FRP.

[2] Norma Portuguesa NP 4305: "Madeira serrada de Pinheiro bravo para estruturas. Classificação visual" - "Visual strength grading of maritime pine".

[3] European Standard EN 408: "Timber structures - Structural timber and glued laminated timber - Determination of some physical and mechanical properties". Draft revision, November 1999. 